\title{
Como e quando o corpo fala: um correlato das respostas psicobiológicas frente ao estresse no voo-livre
}

\author{
How and when the body speaks: a correlation of psychobiological responses to stress in flight-free \\ Giuliano Gomes de Assis Pimentel \\ Grupo de Estudos do Lazer - GEL, Departamento de Educação Física \\ - DEF, Universidade Estadual de Maringá - UEM, Brasil \\ ggapimentel@uem.br
}

Felipe de Oliveira Matos

Grupo de Estudos em Neurociências e Esportes - GENE,

Departamento de Educação Física - DEF, Universidade Estadual de

Maringá - UEM, Brasil

\begin{abstract}
Resumo:
O estresse é um elemento potencializado e ressignificado em esportes de aventura conforme cada sujeito reage aos riscos, desafios e incertezas do ambiente. Considerando essa temática, acompanhamos os momentos mais estressantes no voo-livre, entremeando a reação fisiológica com a fala dos sujeitos pesquisados, no limite da possibilidade de diálogo/confronto sob uma perspectiva biopsicossocial. O recorte privilegiou o esporte de risco como opção de lazer, praticado por pessoas comuns, que obtém na aventura contraponto às tensões e estresse do cotidiano. Para tanto, realizamos observações diretas durante um ano e entrevistamos quatro pilotos. Em complemento, registramos a frequência cardíaca (FC) desses sujeitos durante as diferentes etapas do voo-livre. Conforme os resultados, a FC apresentou patamares agudos e residuais elevados, que são coerentes com a história narrada por cada sujeito. Os pilotos demostraram que a percepção de risco frente à prática esportiva provoca uma tensão necessária para a produção subsequente de sensações transcendentes e prazerosas. Nesse sentido, ponderamos sobre a equação entre a segurança física e emocional na atividade e a percepção subjetiva do risco, ambas vistas como indissociáveis à aventura experimentada.
\end{abstract}

Palavras-Chave: Avaliação de risco, Frequência cardíaca, Estresse, Emoções.

\section{Abstract:}

In adventure sports, stress is a significant element, since each individual reacts to the risks, challenges and uncertainties of the environment. Within this topic, the study follows the most stressful moments in free-flight, interweaving the physiological reaction with the speech of the subjects studied, limiting the possibility of dialogue/confrontation between psychobiological and sociocultural data. They favored risky sports as a leisure option, practised by ordinary people who take adventure as a counterpoint to the tension and stress of everyday life. We carried out one-year direct observation and an interview with four pilots. In addition, we used the behavior of the measured heart rate of these subjects during the different stages of the free-flight. The results showed that the heart rate and the acute high residual levels are consistent with the story narrated by each person. The pilots proved that stress is a voltage required for the subsequent production of transcendent and pleasant feelings. In this sense, it is reflected that the security in the adventure experienced is the result of the equation between the psychophysiological activity and the subjective perception of risk.

KEYWORDS: Risk assessment, Heart rate, Stresse psychological, Emotions.

\section{INTRODUÇÃO}

Embora esteja associado a aspectos negativos no senso-comum, o estresse é um componente importante na vida, havendo, inclusive, formas produzidas culturalmente para provocá-lo, como no caso dos esportes de aventura. $\mathrm{O}$ estresse está presente na forma como qualquer ser reage a situações de perigo, sendo identificável 
por indicadores biológicos como a FC, o cortisol, catecolaminas e células imunitárias periféricas, mesmo em curtos períodos de estresse quando a situação coloca em risco a vida do indivíduo, como, por exemplo, durante um salto-livre (Breen et al., 2016).

O voo-livre é uma dinâmica típica do limiar entre enfrentar ou fugir do perigo (medo), havendo ainda uma lacuna sobre qual é o momento de maior ativação psicobiológica e como praticantes recreativos lidam com essa tensão. Por voo-livre se entenda toda prática de decolagem, ascensão, planeio e decolagem, fazendo uso de tecnologia não-motorizada, no caso a asa-delta ou o parapente. Entre as principais características desse esporte aéreo se destacam: realização em ambiente natural; o esforço na preparação é superior à atividade em si; exige desenvolvimento tecnológico de ponta; a prática é regulada pela Agência Nacional de Aviação Civil; as competições não separam masculino de feminino; o tempo de permanência é mais valorizado que a velocidade de percurso; praticantes necessitam estudar meteorologia; o desempenho envolve gestão dos riscos; o erro nesse quesito está associado à alta prevalência de lesões graves; por isso, é um esporte individual raramente praticado sozinho; a existência do risco é algo que influencia positivamente na escolha desse esporte como opção de lazer; a tecnologia, a técnica e os conhecimentos aeronáuticos podem compensar a má condição física do praticante; exige treinamento prévio e equipamento para o desempenho seguro (Azevedo, Cocchiarale, \& Costa, 2010; Pimentel, 2010; Ramos, 2003).

Considerando os procedimentos de segurança e o desenvolvimento da tecnologia, esses esportes aéreos são caracterizados por baixa incidência de acidentes, mas alto grau de letalidade neles. Em um dos primeiros estudos sobre lesões com asa-delta, Yuill (1977) chegou a 51 pilotos britânicos feridos, dos quais $53 \%$ tiveram fraturas. Já em estudos com pilotos alemães, Schulze et al. (2002) analisaram as notificações obrigatórias de acidentes com parapente. Entre 1997-1999 se observaram, sobremaneira, as lesões na coluna vertebral como aspecto mais preocupante entre os 409 informes. Em um total de 39 acidentes em que foi necessário acionar o paraquedas de emergência, 10 pilotos ficaram gravemente feridos e três faleceram. Embora a maior parte das lesões, incluindo as de coluna, possa ser recuperável (Gauler et al., 2006), os praticantes atestam que o voo-livre é um esporte cujo erro pode ser penalizado com a morte (Parapente Brasil: Histórias e aventuras do vôo livre, 2002).

Dadas essas características, acreditamos que elevados níveis de estresse agudo sejam recorrentes na prática, exigindo que o praticante gere mecanismos de controle da tensão, especialmente nos momentos mais críticos do esporte: decolagem e pouso, além das situações emergenciais durante o planeio (variações não-previstas do clima, pane no equipamento, falha humana). Nesses momentos, os sintomas relatados são pupila dilatada, sudorese, aumento da FC e boca seca (Pimentel, 2010). Há ainda a possibilidade de catatonia, quando o medo frente ao risco (real ou imaginário) deixa o piloto paralisado, sem ação.

Garfinkel \& Critchley (2016) descreveram que o processamento das emoções ligadas ao medo precisa ser avaliado individualmente, pois é potencializado pelas respostas interoceptivas. De acordo com os autores, "a interocepção refere-se à detecção dos estados fisiológicos do corpo”, que é mediada por receptores periféricos (do arco-aórtico e seios carotídeos) e transmitidos ao cérebro onde são processados inicialmente no tronco encefálico, gânglios da base e amigdala, e retransmitido por projeções tálamo-corticais para os córtices orbitofrontal e cingulado anterior, que implicam no comportamento emocional e motivacional. Desse modo, a percepção sobre os estados corporais, pode ressignificar as experiências de cada indivíduo, baseando-se em como cada um enfrentou as demandas ambientais, corporais e cognitivas.

A respeito das fases do voo, elas podem ser designadas tecnicamente em quatro momentos: preparação, decolagem, planeio, pouso (Abdalad, 2005). A preparação para o voo consiste em arrumar o equipamento e se preparar para a decolagem. Neste momento o sujeito utiliza um aparelho chamado espd miter, utilizado para verificar se a velocidade do vento é segura para a decolagem. Este é relatado como um momento muito tenso, pois exige a consideração de muitos fatores de risco na tomada de decisão acerca da realização e procedimentos para o voo. Na decolagem da asa-delta, o piloto corre em direção ao abismo, enquanto no parapente o piloto infla a vela de costas para a rampa, realiza giro de $180^{\circ}$ e corre. 
Durante o voo os praticantes iniciantes se deslocam direto para o campo de pouso. Já os pilotos experientes, conforme sua interação com as condições ambientais (vento e térmica) buscam sustentar-se no ar, entrando em térmicas (ar quente) depreendidas do solo ou deslizando em corrente de ar gerada no choque do vento com a montanha. O pouso é feito por meio de visualização do local escolhido e movimentos de aproximação com diminuição da velocidade (freio gradativo) até o pouso.

Considerando esse modus operandi do esporte, buscamos compreender melhor as atividades miméticas que provocam a busca pelo perigo como forma de estimular respostas prazerosas. Para tal, acompanhamos os momentos com maior potencial para provocar estresse no voo-livre, entremeando as respostas fisiológicas por meio das oscilações na FC com a fala dos sujeitos pesquisados, no limite da possibilidade de diálogo/ confronto entre dados biológicos e socioculturais.

Para tanto, este estudo analisou respostas psicobiológicas de praticantes, por meio da FC e das representações individuais relativas a diferentes etapas do voo-livre a fim de discutir diferentes possibilidades do corpo falar sobre a aventura, ou seja, um relato das experiências vivenciadas e suas respostas fisiológicas durante o voo-livre.

\section{Procedimentos metodológicos}

Este estudo se caracterizou como pesquisa exploratória, descritiva, de cunho qualitativo (Thomas, Nelson \& Silverman, 2007), que buscou associar relatos de experiências vivenciados pelos sujeitos participantes à dados fisiológicos obtidos no trabalho de campo. Deve ser visto como um trabalho exploratório sob variados aspectos, tanto pelo reduzido número da amostra quanto pelo grau de experimentação (no sentido de interagir aspectos da realidade geralmente dissociados nas pesquisas). O protocolo seguiu a Resolução 196/96 e complementares do Conselho Nacional de Saúde do Ministério da Saúde (CNS/MS), com aprovação no comitê de ética da Universidade Estadual de Maringá sob o parecer número 36334.

A população deste estudo foi composta por 24 pilotos amadores de voo-livre que, de forma esporádica ou regular utilizaram a pista de decolagem dos Três Morrinhos, no município de Terra Rica-PR. A amostra constou de quatro indivíduos do sexo masculino, selecionados intencionalmente conforme o critério de acessibilidade e disponibilidade de tempo e equipamentos (02 pilotos de asa-delta e 02 de parapente). Em acréscimo a triagem considerou necessário que os sujeitos se declarassem desportistas recreativos e que buscavam, no voo, uma forma de produzir estresse agudo ("sensação de adrenalina"), aliviando o estresse crônico ou cotidiano.

O sujeito 1, 42 anos de idade, reside na cidade de São Paulo e trabalha como delegado. Pratica parapente e asa delta há quatro anos, por questóes de lazer e como forma de aliviar as tensóes corriqueiras. Faz uso de medicamento para hipertensão, relatando muito estresse no seu dia-a-dia devido à profissão que exerce. Já o sujeito 2, 50 anos, reside na cidade de São Paulo, é comerciante aposentado. É praticante de parapente há seis anos, no tempo livre. O sujeito 3, 35 anos, reside na cidade de Maringá e sua profissão é comerciante. Pratica asa delta há 10 meses. O sujeito 4, 28 anos, reside na cidade de Maringá e sua profissão é chefe de fábrica. É praticante de parapente e de asa delta há quatro meses.

Os praticantes tiveram a FC registrada durante as etapas da prática por meio de monitores cardíacos Accurex (Polar., Finlândia). A coleta de dados foi realizada em condições climáticas similares, evitando esse fator interveniente no resultado entre sujeitos. Também foi verificada a FC de repouso dos pesquisados. Nesse sentido, a ideia é combinar - ainda que de forma restrita - diferentes fontes para compreender características biodinâmicas e socioculturais presentes nas quatro etapas do voo-livre.

Para a aquisição das representações coletivas acerca das emoções vivenciadas pelos sujeitos utilizamos entrevistas semiestruturadas, enfatizando a percepção dos sujeitos sobre si mesmos, seus cuidados e as sensações relacionadas à prática de preparação, decolagem, planeio e pouso nesse esporte de aventura. As entrevistas foram gravadas e posteriormente transcritas em arquivos no formato Word. Realizamos análise 
das falas a partir da identificação de categorias nativas, as quais condensam o conhecimento empírico compartilhado entre os praticantes a respeito de como percebem a realidade.

Para tanto, o estudo foi influenciado pela Teoria Simbólica (Elias, 1989), a qual unifica os estudos do autor em relação à importância de observar como natureza e cultura compõe uma unidade. Portanto, o ser indivíduo-social é biologia, psiquê e social para produzir cultura. Os desdobramentos da análise integrada na Educação Física (Corrêa et al, 2020) nos incentivaram a este estudo, em que situamos o voo-livre como um descontrole-controlado de busca por emoções, que ao mesmo tempo estão presentes em outros animais nas condutas de risco evolutivas mas se diferenciam no ser humano por terem significados. Entendemos, portanto, que o movimento humano no voo-livre é produtor de sensações psicofisiológicas que precisam ser interpretadas à luz das categorias nativas de seus praticantes.

\section{Resultados E Discuss Ão}

Realizamos uma estatística descritiva dos dados da FC, os quais são apresentados indicando os percentuais da $\mathrm{FC}$ em relação à frequência cardíaca máxima ( $\mathrm{FC}_{\text {Máx }}$ ), que foi estipulada com uso da fórmula 220 - idade (Karvonen, Kentala, \& Mustala, 1957), a qual possui boa correlação com a FC $_{\text {Máx }}$ encontrada em testes de indivíduos sedentários (Camarda et al., 2008).

As fases do voo foram caracterizadas pelas ações de preparar, decolar, planar (voo propriamente dito), pousar e, por fim, desmontar (asa-delta) ou dobrar (parapente) e acondicionar o equipamento. A tabela 1 mostra a FC nos distintos momentos do voo.

TABELA 1

Valores da FC nas diferentes fases do voo

\begin{tabular}{|c|c|c|c|c|c|c|c|c|c|c|c|c|}
\hline \multirow[b]{2}{*}{ Sujeitos } & \multicolumn{2}{|c|}{$\begin{array}{l}\mathrm{FC} \mathrm{de} \\
\text { repouso }\end{array}$} & \multicolumn{2}{|c|}{ Preparar } & \multicolumn{2}{|c|}{ Decolar } & \multicolumn{2}{|c|}{ Planar } & \multicolumn{2}{|c|}{ Pousar } & \multicolumn{2}{|c|}{$\begin{array}{l}\text { Desmontar/ } \\
\text { Dobrar }\end{array}$} \\
\hline & $\mathrm{bpm}$ & $\%$ & $\mathrm{bpm}$ & $\%$ & $\mathrm{bpm}$ & $\%$ & $\mathrm{bpm}$ & $\%$ & $\mathrm{bpm}$ & $\%$ & $\mathrm{bpm}$ & $\%$ \\
\hline 1 & 71 & 39 & 112 & 63 & 136 & 76 & 140 & 79 & 114 & 64 & 96 & 54 \\
\hline 2 & 76 & 45 & 144 & 85 & 146 & 86 & 147 & 87 & 148 & 87 & 140 & 82 \\
\hline 3 & 80 & 43 & 110 & 59 & 155 & 84 & 159 & 86 & 188 & 102 & 171 & 92 \\
\hline 4 & 76 & 40 & 174 & 91 & 200 & 104 & 171 & 89 & 190 & 99 & 178 & 93 \\
\hline
\end{tabular}

Os valores da FC de repouso sugerem a condição recreativa da prática do voo pelos indivíduos, visto que não correspondem aos de atletas treinados com alto nível de condicionamento físico. Chama atenção em dois pilotos a condição de risco cardíaco (Wilmore, Costill, \& Kennedy, 2013) em percentuais próximos à $\mathrm{FC}_{\text {Máx }}$ em diferentes fases do voo. No entanto, a reatividade cardiovascular frente ao contexto, pode ter causas diversas (Lipp, Frare, \& Santos, 2007) que serão inferidas ao longo da discussão.

Na preparação para o voo, a FC de todos os indivíduos aumentou, perfazendo uma média de incremento de $78 \%$ frente à FC de repouso. Além do esforço empregado na montagem do material, há de se considerar a ansiedade remetida a esse momento. Logo, é um momento de concentração e busca de autocontrole. O sujeito 3 afirma: "Tem uma questão importante que eu considero bastante; é toda uma preparação do equipamento na hora da montagem. Você tem que montar com calma..." cada piloto é responsável pela gestão dos riscos que corre, iniciando pela montagem de seu material. Logo, esse é um momento decisivo para as fases posteriores. 
A decolagem é um momento crítico, ocorre um incremento na FC correspondente ao estresse característico do momento. Wilmore et al. (2013) postulam que antes do início da atividade física em si, a FC pré-exercício geralmente aumenta bem acima do valor de repouso. É a denominada “resposta antecipatória”, a qual é devida à liberação do neurotransmissor noradrenalina pelo sistema nervoso simpático e pelo hormônio adrenalina pelas glândulas adrenais.

Durante o pouso, parte dos sujeitos experimenta aumentos nos valores de FC, situando que esse momento de entrada em solo pode ser estressante, mas não afeta todos os sujeitos estudados. Aqueles mais experientes, mais velhos e utilizando parapente (sujeitos 1 e 2) apresentaram menor FC no pouso quando comparados aos sujeitos mais jovens, menos experientes e usando asa-delta. Devido ao tamanho amostral do trabalho não é coerente realizar inferências, mas - a partir dessa hipótese - é sugestivo pensar em novos estudos que considerem essas variáveis na determinação do estresse pela FC durante a fase de pouso.

Discutindo mais os resultados por fase do voo, esses dados de FC se alinham com as representações sociais e observação direta da população do estudo, situando a problemática do estresse durante a decolagem. $\mathrm{O}$ estado clássico de estresse agudo, no qual o corpo é preparado para enfrentar ou fugir da situação estressora, parece ser um ponto nevrálgico do esporte de aventura:

"Fui decolar na rampa Sul eu fiquei lá enraizado. Então eu pensei assim: eu vou pra morrer, mas tenho que fazer isso aí. Nunca passei tanto medo na minha vida. Deus me livre. O coração não batia, ele parou. Foi aterrorizante esse primeiro voo, mas venci. Quebrou o tabu. Depois fizemos o segundo. Com uma dificuldade. Eu punha a asa nas costas, mas não queria ir. Não queria ir de jeito nenhum e por outro lado queria. O jeito que eu achei de fazer isso foi: eu montava o equipamento, colocava a asa na rampa e ficava montado embaixo. Punha a asa no ombro, punha a asa no chão. Vou não, vou, vou, não vou. De repente, parecia que era um troço que dava em mim, levantava a asa, saia correndo e voava”. (Sujeito 3)

Portanto, a tomada de decisão (considerando fatores de risco e procedimentos de segurança) e a execução da decolagem parecem preencher o ápice da experiência de superação, (o que, conforme o quadro 1 é acompanhado pelo maior incremento percentual na FC). Na fala do Sujeito 01: "E então é aquele minuto ou segundo que você tem que decidir: 'tenho condições de fazer, sou capaz de fazer e quero fazer' e você corre para o vento". Essa é a parte de tensão máxima, com vários indicadores psicossomáticos de estresse quando o risco é percebido mais intensamente. Os pilotos relatam em seguida a experimentação de um momento de distensão, iniciando a apreciação da aventura.

Segundo afirma o sujeito 3, "o voo em si é a parte mais tranquila que tem. Esse é o lado bom. Depois [para pousar] é que você tem que estar atento na direção do vento. Esse é um ponto que tem que tomar bastante cuidado". É interessante, conforme as falas, que uns pilotos venham a sentir-se mais ameaçados em uma ou outra fase do voo (geralmente a decolagem e o pouso), mantendo coesão quando afirmam ser o momento de planeio (o voo em si) aquele mais prazeroso e seguro. Nesse ponto, os relatos são recorrentes quanto ao prazer da atividade.

“A adrenalina é viciante. Você quando tem uma descarga de adrenalina passa aquela situação de viver intensamente cada segundo. Cada minuto que você está naquela situação é como se fosse um ano. Então quando você pousa, está tudo certo, deu tudo certo. Primeiro vem aquela sensação de conquista, e depois aquela sensação de relaxamento. Então é um remédio; é um santo remédio" (Sujeito 1)

"Eu voo porque é gostoso voar, só isso. O medo, a adrenalina pra a gente ter esse prazer de voar a gente supera" (Sujeito 2)

"Sensação maravilhosa, cara. Todo mundo deveria fazer" (Sujeito 4)

De certa forma, a dinâmica tensão-alívio verificada no esporte de aventura é posta como estratégia de enfrentamento ao estresse vivido na atividade, sendo, às vezes, imaginada como compensação também ao estresse cotidiano dos sujeitos e um contraponto para esquecer as obrigações do dia-a-dia. Irrefragavelmente, a interpretação desse fenômeno nesses termos de suspensão temporária da realidade soluciona parte do questionamento sobre como o estresse é superado graças ao enfrentamento do risco. Em Elias (1989) acrescentaríamos que o uso de tecnologias avançadas para garantir o controle dos riscos concomitante à intensa excitação biológica do instinto de sobrevivência, é um ganho civilizatório. Cantorani \& Amaral 
(2009) em referência a Elias, complementam que "não é simplesmente, como muitas vezes se pensa, uma libertação das tensões, mas a renovação dessa medida de tensão, que é um ingrediente essencial da saúde mental".

O entendimento de que tensão na dose certa é benéfico, pode ter respaldo tanto psicológico quanto fisiológico. Segundo Samulski, Chagas, \& Nitsch (1996) o estresse é necessário à vida para a manutenção e aperfeiçoamento da capacidade funcional, autoproteção e conhecimento dos próprios limites. Em acréscimo, o estresse pode ser vantajoso, especialmente se o comportamento a ser realizado contém atividade corporal. Em situações de desequilíbrio orgânico os hormônios, entre os quais a endorfina, entram em cena a fim de amenizar ou restabelecer a homeostase (psicofisiológica).

As endorfinas desempenham um papel importante no controle do estresse, auxiliando desde o controle da dor até a sensação de bem-estar proporcionada pela prática da atividade física. Desta forma, a b-endorfina é liberada em situações de estresse do organismo e parece estar envolvida na promoção de um efeito analgésico, e também na melhora dos aspectos emocionais (Graeff, 2003).

Por outro lado, vale ressaltar que o prazer decorrente dessa atividade hormonal é capaz de levar o cérebro à mesma intensidade que a observada em usuários de substâncias psicoativas (Sher, 2001). Logo, há de se pensar também se esse tipo de atividade pode gerar algum tipo de dependência ou crise de abstinência, tendo em vista que as falas não só se remetem ao prazer da atividade como a necessidade em repeti-la.

"Rapaz, acho que é a melhor coisa, heim!? Acho que o cara pode estar até com uma dor em algum lugar do corpo que lá em cima nem percebe. A sensação melhor que tem. Eu acho que a gente fica mais calmo. Fica mais tranquilo. Passa a semana que a gente nem vê. A única coisa que aumentou foi a vontade do próximo fim-de-semana chegar logo. Dá uma aliviada. Dá uma ajuda legal. Se sente mais novo" (Sujeito 3).

Ao longo da história desenvolvemos diferentes representações socioculturais para atingir esses objetivos, sejam por meio de psicotrópicos, do esporte ou da aventura. Portanto, podemos considerar que a busca pelo prazer e a superação de limites é algo que permeia a sociedade e nos faz humanos. Até o momento, já identificamos que os pilotos recreativos buscam essa tensão aguda como forma de alívio de um estresse cotidiano, mas isso não é apenas uma compensação, conforme veremos.

A fase de aterrissagem é considerada por muitos pilotos como um novo momento de tensão, equivalente à decolagem. Se para sair do morro e ingressar no ar, o piloto vive a apreensão da troca de ambiente, o pouso significa o retorno ao solo, com os diferentes riscos associados a uma aterrissagem feita em local impróprio (arborizar) ou de forma desequilibrada, tombando na aterrissagem (crechar).

A dificuldade na aterrissagem foi sentida por um piloto que pousara sem estabilidade. A má aproximação e o desequilíbrio são associados a uma falha na comunicação do corpo com o equipamento, num momento já de cansaço. Além do cálculo equivocado da distância, o piloto não nivela adequadamente os lados da asa, fazendo com que caia para frente ou lateralmente. Um dos pilotos, em seus primeiros voos, lembra-se de realizar uma boa aproximação, seguindo em linha reta contra o vento. Porém, ao tocar o solo, já não estava mais alinhado a ele: "A gente perde a noção do chão. Embora a gente não pouse com força no chão, a gente perde o equilíbrio. Até pegar o equilíbrio certo demora um pouco" (Sujeito 4).

Em um esforço de síntese sobre as fases e a partir dos dados coletados, se tem o seguinte: a preparação costuma ser silenciosa por causa da concentração; os minutos antecedentes à decolagem representam um aumento na FC, embora os sujeitos não apresentem outros sinais fisiológicos de estresse; a decolagem é acompanhada de sinais complementares de estresse (sudorese, tremor nos membros, boca seca, dilatação da pupila e irritação) e o maior pico da FC; o voo em si, quanto mais longo for, é caracterizado pelo estado de equilíbrio, até porque é o momento de menor incidência de acidentes no esporte; o estresse no pouso depende de condições diversas, como as atmosféricas, mas é algo menos imprevisível que a decolagem e, qualitativamente, a experiência do piloto (incluindo o tempo de adaptação ao modelo de asa ou parapente) é determinante. Mas, observando algumas respostas idiossincráticas, se pode chegar a uma análise mais minuciosa e menos generalista da relação de cada piloto com o estresse. 
Durante o preparo para a decolagem o sujeito 1 teve algumas mudanças na sua FC, variando de 112 a 127 batimentos por minuto (bpm). No momento do salto, seus batimentos foram para $136 \mathrm{bpm}$. A média da FC do indivíduo foi de $140 \mathrm{bpm}$, seu esforço foi de $79 \%$ de sua $\mathrm{FC}_{\text {Máx }}$ É importante ponderar que a resposta cardíaca do sujeito 1 pode ter sido mascarada pela medicação para hipertensão, já que essa atenua as respostas hemodinâmicas. Todavia, outro aspecto a ser observado é que esse indivíduo relatou estar adaptado ao estresse. Conforme Graeff (2003) quando os estímulos estressores se tornam crônicos, a resposta ao estressor diminui, podendo haver uma antecipação às respostas homeostáticas.

O sujeito 2 teve sua FC mais elevada na preparação para o voo, a qual se manteve estável nos momentos de decolagem e planeio. Este sujeito se arriscou um pouco na hora de decolar, pois o vento estava inconstante e forte no momento da decolagem. Foi relatado por ele que suas mãos começaram a ficar suadas, sua boca secou e a FC se elevou, o que expressa traços de reatividade somática ao estresse.

Sobre a influência de fatores ambientais na atividade, o pouso do sujeito 3 foi dificultado por uma térmica (Breen et al., 2016) e o bico de sua asa-delta elevou-se, forçando o piloto a pousar distante do ponto de aterrissagem. Nesse momento do pouso, quando teve que lidar com o imprevisto, a FC do sujeito 3 elevase, denotando o momento de grande estresse, principalmente devido à pouca prática do piloto com térmicas, uma vez que o mesmo pratica a atividade há apenas dez meses. O estresse pôde ser atribuído tanto pelo esforço físico para controlar a asa frente a uma força natural como pelo susto (a térmica é invisível).

Segundo estimativas da literatura técnica, o rendimento ótimo em térmicas é decorrente de muita experiência. Estima-se que sejam necessários no mínimo 50 a 200 voos, dependendo da evolução do piloto, de variações do equipamento, do local de prática (se possui muitas térmicas), da sensibilidade e nível de estudo em meteorologia (Cavalcanti, 2004).

O festival de voo-livre no qual foram coletados os dados foi a primeira vez em que o sujeito 04 saltou de asa-delta sozinho. Por essa condição, ao montar o equipamento sua FC já estava alta. No momento que o sujeito 4 estava preparado para saltar recebeu uma mensagem do seu instrutor informando que o vento estava muito forte e, portanto, ele não deveria decolar naquele momento. Ao receber a mensagem sua FC chegou a $200 \mathrm{bpm}$, valor superior à sua $\mathrm{FC}_{\text {Máx }}$ prevista. Neste momento o sujeito relatou que sua boca estava seca e suas mãos começaram a suar. Durante a observação pudemos perceber também que sua respiração estava acelerada e a fala aparentava cansaço.

É importante frisar que o organismo entra imediatamente em alerta quando a pessoa percebe ameaça ou perigo, o volume sanguíneo circulante aumenta para que nutrientes cheguem à musculatura esquelética e o indivíduo possa responder adequadamente à situação. Segundo Weineck (2005) o aumento da FC permite que o sangue circule mais rapidamente e leve oxigênio e nutrientes aos tecidos, já o aumento frequência respiratória é necessário para que o organismo capte e absolva mais oxigênio.

Após a tentativa de decolagem, o sujeito 4 virou sua asa para esperar um momento mais oportuno para a decolagem. Sua FC baixou para 158 bpm. Durante o planeio sua FC média manteve-se em $89 \%$ da FC Máx prevista. No momento do pouso houve um novo aumento da FC, seguido da recuperação da mesma durante o desmonte do equipamento foi lenta.

Apesar das particularidades como cada sujeito reagiu fisiologicamente às fases do voo, o estresse na fase de decolagem foi comum a todos, com pico da FC nesse momento, seguido de uma tentativa de equilíbrio durante o planeio. A FC nos momentos que antecedem o voo aumentou em todos os sujeitos. Essa elevação da FC está diretamente relacionada à percepção de estresse e as respostas frente à ansiedade. Em níveis aceitáveis, esse resultado é considerado fundamental para melhorar o desempenho. Mas o excesso de tensão levará ao aumento da probabilidade de o praticante ver como ameaçadores fenômenos que não são propriamente ditos perigosos, deixando de aproveitar sua atividade.

Já baixos níveis de estresse, podem estar relacionados a uma leitura inadequada dos perigos, sujeitando o piloto a mais riscos de acidente, o que nos remete à ideia de redoma sensorial na aventura (Paixão, Tucher, Costa, \& Gabriel, 2010). Esse conceito considera quando os sentidos do praticante se acostumam aos 
estímulos sensoriais extraordinários, ao invés de aprimorar seus sentidos e deixa-lo em prontidão. Uma vez que tais eventos são pouco decorrentes o indivíduo passa a negligenciá-los.

Todavia, analisando a pessoa em sua individualidade psicológica, biológica e social, fica claro que diante de estímulos iguais, pessoas diferentes reagem distintamente e a mesma pessoa em diferentes situações reage de forma diferenciada (Samulski et al., 1996). A FC do sujeito 1, por exemplo, não pode ser generalizada para a pesquisa, pois ele utiliza medicamentos para hipertensão, o que possivelmente distingue suas respostas hemodinâmicas das dos demais. Por outro lado, é um sujeito adaptado ao estresse e realiza treinamento físico.

Assim, quando se observa a questão da FC frente ao risco, se sabe que diferentes fatores podem interferir nessa variável e, portanto, na sua acuidade. Entre as variáveis pode-se citar o condicionamento corporal, a percepção subjetiva do praticante, as condições meteorológicas, o capital social presente e o estresse psíquico, que pode ocorrer tanto durante a atividade como antes da competição.

É importante considerar que há uma reciprocidade entre estresse psíquico e somático, visto que o corpo não é um ente dicotomizado. Assim, uma esfera interfere na outra. Durante o estado pré-competitivo, sem a presença do esforço, ocorrem manifestações de ordem fisiológica em cadeia, a saber: (a) Maior liberação de catecolaminas (adrenalina e noradrenalina); b) Maior liberação de glicorticóides; (c) Aumento da FC; (d) Aumento da pressão sanguínea; (e) Aumento da frequência respiratória, do volume de inspiração respiratório e do volume - minuto respiratório; (f) Aumento do tônus muscular (Weineck, 2005).

A mudança do estado no período pré-competitivo pode ocorrer algumas horas antes da carga corporal ou apenas um pouco antes. Muita tensão no período pré-competitivo, numa competição com altas expectativas, pode reduzir a capacidade de desempenho esportivo. Para Samulski et al. (1996) um dos fatores com influência mais significativa na qualidade da performance é o grau de ansiedade estado durante o tempo que precede a competição (ansiedade pré-competitiva).

Percebe-se que o estresse pré-competitivo pode ser decisório durante a competição. Cavalcanti (2004), a respeito do voo-livre, opina que apenas o otimismo (psíquico), sem a aplicação física e técnica, não é suficiente para desenrolar os objetivos, embora seja um poderoso veículo no caminho da realização. No entanto, todos os domínios técnicos e físicos, sem a confluência psíquica, de nada valem, pois a obstrução mental é uma barreira das mais difíceis de transpor. A ansiedade interfere no desempenho, pois o piloto demora mais para tomar decisões, toma riscos desnecessários e esquece princípios básicos para a realização do voo (Cavalcanti, 2004).

O voo-livre depende de uma conjunção de fatores, exigindo capacidade em organizar informações complexas, o que demanda prática. Nas palavras de um piloto, se deve "ter o pensamento mais rápido que o movimento", isto é, o sucesso na atividade depende de antecipação cognitiva frente às possíveis ocorrências. Logo, um resultado ruim na confiança dos pilotos seria um fator preocupante, se vier a gerar bloqueios, embora, por outro lado, pode significar indiretamente o nível de alerta, pois tanto o excesso de confiança como níveis baixos aumentam a probabilidade de falhas.

Com relação aos aspectos biológicos do estresse todos os indivíduos se sentiram mais nervosos e tensos. Apresentaram acidez no estômago, taquicardia e rigidez muscular. Hipoteticamente se pode pensar que essas reações somáticas estão presentes porque apesar dos pilotos já serem capazes de calcular (racionalizar) o risco, o inconsciente ainda cria alertas e defesas contra qualquer pretensão de se lançar em um precipício. Assim, a ansiedade-somática seria proveniente do instinto de sobrevivência, pois o medo muitas vezes evita que nos coloquemos em situações que possam causar danos à integridade do nosso organismo. Por outro lado, os pilotos tentam sublimar esses alarmes porque, talvez, já não sejam percebidos tão somente como reações indesejáveis, mas, também, como emoções indissociáveis da prática. Logo, possivelmente, há convivência tolerância com os -inevitáveis- efeitos somáticos do estresse psicológico.

Outro aspecto a ponderar é que, "emoções distintas geram reatividades diferentes” (Lipp et al., 2007), bem como pessoas com dificuldades em lidar com as emoções (alexitimia) apresentam reatividade cardiovascular mais elevada quando comparadas a sujeitos assertivos. Logo, além da emoção da aventura poder agir sobre o 
aumento da FC e da pressão arterial diastólica, o modo como cada sujeito reage a essas emoções interfere na magnitude desses parâmetros. Como, a ansiedade dos pilotos pode ser melhorada, é importante pensar em técnicas psicológicas de suporte ao enfrentamento do risco percebido pelos mesmos. A ansiedade bloqueia a discriminação das emoções, sendo um fator que interfere no rendimento de discernimento frente ao risco.

No geral, foi perceptível que esses participantes recreativos obtiveram resultados ambíguos, dando a entender que, numa tarefa complexa como voar, a capacidade de controlar as emoções é tanto mais necessária quanto mais difícil de obter, quando confrontada com esportes menos letais (Breen et al., 2016).

Assim, o estresse de fundo psicológico deve ser considerado em relação à saúde. Não se trata de desaconselhar a atividade, mas de pensar em mecanismos de autocuidado para refrear os efeitos deletérios dessa ansiedade somática. Aqui realizamos a ponderação de que, simbolicamente, essas reações corporais possam ser vistas como um aspecto importante tanto à segurança quanto à recompensa psíquica em superar o medo. Esses fatores precisam ser considerados.

As "pistas" do estudo vêm levando à importância de o corpo suportar as reações somáticas do estresse frente às ameaças do risco esportivo. Por isso, o condicionamento corporal tende a ganhar destaque à saúde dos praticantes e o controle do estresse (ou de seus efeitos colaterais). Conforme os dados obtidos, percebe-se, também, a importância da atividade física para quem pratica o voo-livre.

Um exemplo foi o sujeito 3, que necessitou de um esforço adicional para poder controlar a térmica durante o pouso. Segundo a literatura técnica aponta, não é necessário um condicionamento físico especial para a prática, porém a mesma será mais bem executada por quem esteja bem fisicamente. Especialmente nos momentos críticos e para aumentar o tempo de permanência no ar, o piloto fisicamente e tecnicamente treinado terá melhor desempenho e recuperação mais rápida. Inclusive nos acidentes leves, possui mais chances de sair ileso alguém que não possui excesso de peso, com pouca força muscular, articulações, tendões e ligamentos frágeis, e com pouca flexibilidade articular (Pagen, 2003; Semenoff, 1998).

Como os pilotos pesquisados mostraram que o estresse psíquico é uma tensão necessária para o subsequente relaxamento (ilustrada pela produção de opiáceos), é importante que esses sujeitos se valham de dispositivos preventivos para equacionar a segurança fisiológica na atividade com a percepção subjetiva de risco vista como indissociável à aventura experimentada. Considerando, portanto, a possível relação entre condicionamento físico e capacidade de resiliência em situações estressantes, há orientação de especialista quanto a importância de treinamento combinado (força, flexibilidade, coordenação, equilíbrio e principalmente atividades aeróbias) para se obter níveis menores de estímulo cardiovascular durante e após o estresse (Nunomura, Teixeira, \& Fernandes, 2009).

As falas do corpo no voo-livre também são traduzíveis em categorias nativas. No estudo, identificamos que os pilotos se remetem à paralisia pelo medo como "enraizar" ou "cristalizar", o que é comum no momento de decolar. A célebre questão de enfrentar ou fugir, é ressignifica por "correr para o vento" versus "enraizar". A consciência de quais são os medos aparecem nos revezes do "arborizar" e do "crechar", mas estes perigos indesejáveis são percebidos como constituintes da emoção de "adrenalina” ou "adrenar", que seria a excitação mais intensa que é seguida de sentimentos de paz interior na fase de voo.

À nossa análise, os sujeitos tratam as fases do voo como etapas rituais, nas quais eles possuem um conhecimento partilhado sobre como o corpo é atravessado por emoçóes intensas recorrentes em cada momento. Por isso, supomos que o enfrentamento dos riscos, por meio do voo-livre, diz respeito também aos significados desenvolvidos pelos sujeitos sobre a própria existência. Logo, não é apenas uma busca fisiológica por excitação. O processo civilizatório humano, na perspectiva elisiana, envolve justamente essa capacidade de desenvolvermos controles psicossociais de nossas pulsões. Criamos uma segunda natureza, refinando as emoções, mas elas estão lá e se manifestam, conforme os dados de FC reforçam.

Logo, concluindo nossas análises, defendemos que o enfrentamento esportivo dos riscos, revela a integração biossocial do que é a complexidade humana, desde as respostas fisiológicas mais instintivas até os mecanismos civilizatórios que a sociedade desenvolve, com auxílio de novas tecnologias, para aprimorar o 
autocontrole humano, na sua insaciável busca por significado. Frente a esse entendimento, qual é o papel da Educação Física na intervenção junto ao voo-livre, numa perspectiva de integração entre biologia e cultura? Defendemos que é a educação corporal não-dicotômica para a vivência dos riscos.

Em se tratando de práticas que exigem o controle de si sobre o risco de acidentes letais, a aptidão física é interessante fator de proteção. Porém, talvez este não seja o principal fator de gestão dos riscos, pois restringe o debate da responsabilidade sobre o indivíduo. Definir o que é risco e como geri-lo é certamente uma questão de poder. Isso significa que as respostas técnicas e científicas tradicionais, embora necessárias, não são suficientes para suprimir as desconfianças populacionais sobre os mecanismos de controle (Slovic, 2010).

A esse respeito, é importante situar que o voo-livre, entre outras atividades de aventura, pode ser tomado como uma prática contemporânea ancorada no paradoxo da segurança-risco. Tal fenômeno é engendrado pelo biopoder no sentido da antecipação, prevenção e auto responsabilização do sujeito sobre suas atitudes. Significa, portanto, um impasse entre uma sociedade que desenvolve mecanismos para reduzir os riscos corporais, mas, por outro lado, aumenta a democratização de experiências que expõe esse corpo ao dispêndio da vida em situações de risco (Gomes, 2009).

Esse paradoxo risco-segurança, neste estudo, pode ser visualizado na preocupação quanto aos cuidados necessários para o piloto sofrer menor estresse psíquico e somático, mas, ao mesmo tempo, esses sintomas são desejados no sentido de constituírem obstáculos que o piloto irá superar na sua aventura. Enquanto a mídia reverbera ditames sobre práticas corporais que previnem riscos futuros à saúde (Vaz, Pombo, Fantinato, \& Pecly, 2007), chega a ser contraditória a também produção dessas outras práticas, cuja aproximação (virtual e atual) com o risco, alimenta a psicossomatização da aventura.

Por isso Slovic (2010) enfatiza ser necessário reconhecer que a abordagem em voga na gestão dos riscos difere das soluções produzidas pelas pessoas. Além dos riscos envolverem incertezas de difícil medição, esse elemento gera percepções e sentimentos humanos. Segundo esse autor, o ideal seria tomar os sujeitos afetados pelas práticas complexas como parceiros legítimos no exercício de avaliação e gestão de riscos. O autor reconhece que não se trata de uma proposta fácil, mas há de se convir que, dados os múltiplos desvios presentes nas práticas de aventura (na superação dos limites do corpo, nas desobediências das regras de segurança), a epidemiologia e a prevenção dos riscos esportivos receberiam um novo impulso em longo prazo.

\section{CONSIDERAÇÕES FINAIS}

$\mathrm{Na}$ contemporaneidade, saber correr riscos ainda é um valor socioeconomicamente positivado, levando inclusive a processos de autoconhecimento. Logo, parece que os dispositivos de controle e segurança são admitidos como importantes na manutenção da vida, mas condicionados a estarem em consonância com a produção de emoções fortes nessas práticas de aventura, essenciais para esses sujeitos absorverem liminares experiências de vida.

O voo-livre é um esporte aéreo de aventura que, epidemiologicamente, possui baixa incidência e alta letalidade de acidentes. $\mathrm{O}$ risco é desejado como componente da experiência. Isso significa que o estresse agudo é um elemento presente na prática, tendo efeitos psicobiológicos sobre o praticante e alimentando seu imaginário sobre a atividade. $\mathrm{O}$ estado da arte sobre acidentes no voo-livre é avançado fora do Brasil, mas fatores biodinâmicos e socioculturais associados a essa prática ainda são carentes em estudos.

Essa pesquisa teve inconsistências na amostragem, na seleção de sujeitos heterogêneos e no instrumental indireto, com aplicação em diferentes datas. Resumindo, o principal limite do estudo é sua característica exploratória. Daí, pois, que sua maior contribuição é insinuar relações e possibilidades de investigação em um número maior de praticantes de voo-livre.

A partir dos quatro sujeitos estudados nenhuma relação se demonstrou suficientemente forte para ensejar uma causalidade sobre as demais. Todos os aspectos parecem se afetar reciprocamente. Como visto, a idade, o sedentarismo e a inexperiência de um piloto mostraram relações com sua ansiedade e estresse cardíaco, mas 
não significaram efetivamente que mais experiência e condicionamento fossem suficientes para explicar FC mais equilibrada, tendo em vista haver em cada caso um momento imprevisto ou um remédio interveniente para relativizar qualquer linearidade.

Concluímos com algumas provocações para pensar:

A reatividade cardiovascular é coerente com a representação social que pilotos fazem sobre a tensão em cada fase do voo, sendo a decolagem o momento de maior estresse, seguida do pouso - pois epidemiologicamente representam os pontos críticos de acidentes. Já o planeio seria o momento de distensão e maior controle sobre a segurança. $\mathrm{O}$ risco presente nessa atividade aumenta o estresse, mas também parece estar associado à maior liberação de b-endorfinas e, portanto, ser representado como prazeroso.

Aspectos como tipo de equipamento utilizado, experiência e condicionamento físico parecem ser indicadores sugestivos de variação na FC durante os momentos decisivos do esporte. Logo há de se pensar no quanto a desigualdade de capital (econômico, social e corporal) responde pela diferença nos riscos do e sobre o sujeito.

A relação positivada ao enfrentamento dos riscos (que não veem como riscos, porque adotam seus modos de operar a segurança) quando comparados com os sintomas físicos do estresse, aponta para possíveis implicações de fatores psíquicos "não-conscientes" no enfrentamento do risco esportivo, o que, se infere, ter relações recíprocas com a representação social do voo.

O estresse agudo que ocorre durante a prática do voo-livre é percebido como necessário pelo praticante, pois através desta prática os indivíduos entendem combater o estresse do seu cotidiano e terem sensação de bem-estar, que, em alguns casos é transcendente, noutros catártico. Logo, o que o corpo fala sobre o estresse transcende da condição reativa biológica para evidenciarmos um sofisticado constructo sociocultural.

$\mathrm{Na}$ contemporaneidade, a questão do risco buscado como opção de lazer, deve ser visto não somente em seus efeitos psicobiológicos imediatos ou em suas ações compensatórias, mas como um investimento que os sujeitos realizam em certas práticas corporais em busca do desenvolvimento de si. Numa sociedade permeada de riscos que fogem ao controle individual e que, paradoxalmente, exige das pessoas a responsabilidade pela própria saúde, a aventura esportiva conota ser uma experiência pessoal em busca da autonomia e do autoconhecimento. Esse comportamento humano, mediado por fortes emoções, parece responder à dialética de sair da segurança para a insegurança em busca de um novo estágio de equilíbrio.

Assim, aspectos biodinâmicos, psicossociais e socioculturais apresentam interfaces e afetam-se mutuamente. Longe da causalidade linear, essas dimensões parecem complementarmente decisivas nos arranjos pedagógicos que o esporte de aventura, no contexto pesquisado, assume. Neste sentido, o diálogo da promoção da saúde nesses contextos carece dialogar com a complexidade dos aspectos objetivos e subjetivos presentes na opção da aventura como opção esportiva de lazer. Assim, a educação física pode aprimorar a leitura biopsicossocial do corpo na vivência dos riscos com vistas à atuação integrada sobre essas dimensões.

\section{Agradecimentos}

Gostaríamos de expressar nossa gratidão à Andréa Schiavone Pereira Coelho pelo auxílio e trabalho nas coletas de dados durante a realização desse trabalho.

\section{REFERÊNCIAS}

Abdalad, L. S. (2005). Mulheres e vôo livre: o universo feminino nos esportes de aventura e risco. Rio de Janeiro; Niterói: Nitpress.

Azevedo, S. L. G. de, Cocchiarale, N. F. de B. R., \& Costa, V. L. de M. (2010). A influência do risco-aventura no processo de coesão das diferentes comunidades do voo livre. Movimento (ESEFID/UFRGS), 16(3), 257-276. h ttps://doi.org/10.22456/1982-8918.9657 
Breen, M. S., Beliakova-Bethell, N., Mujica-Parodi, L. R., Carlson, J. M., Ensign, W. Y., Woelk, C. H., \& Rana, B. K. (2016). Acute psychological stress induces short-term variable immune response. Brain, Behavior, and Immunity, 53, 172-182. https://doi.org/10.1016/j.bbi.2015.10.008

Camarda, S. R. de A., Tebexreni, A. S., Páfaro, C. N., Sasai, F. B., Tambeiro, V. L., Juliano, Y., \& Barros Neto, T. L. de. (2008). Comparação da freqüência cardíaca máxima medida com as fórmulas de predição propostas por Karvonen e Tanaka. Arquivos Brasileiros de Cardiologia, 91(5), 311-314. https://doi.org/10.1590/S0066-782 X2008001700005

Cantorani, J. R. H., \& Amaral, S. C. F. (2009). Interfaces entre cultura do lazer e o acesso ao sedentarismo. Lecturas, Educación Física y Deportes, Revista Digital, 14(133). Recuperado de https://www.efdeportes.com/efd133/cul tura-do-lazer-e-o-acesso-ao-sedentarismo.htm

Cavalcanti, B. S. (2004). Vôo livre: curso avançado de cross country e competições. Curitiba.

Corrêa, L. V. O. M; Fugi, N. C; Herold Júnior, C. Pimentel, G. G. A. (2020) A dicotomia biologia versus cultura no campo da Educação Física e uma prospectiva ontológica integrada. The Journal of The Latin American SocioCultural Studies.fSport (Alesde), 12 (1),p. 124-140. https://revistas.ufpr.br/alesde/article/view/73274/40885

Elias, N. (1989). The Symbol Theory: An Introduction, Part One. Theory, Culture \& Society, 6(2), 169-217. https:/ /doi.org/10.1177/026327689006002002

Garfinkel, S. N., \& Critchley, H. D. (2016). Threat and the Body: How the Heart Supports Fear Processing. Trends in Cognitive Sciences, 20(1), 34-46. https://doi.org/10.1016/j.tics.2015.10.005

Gauler, R., Moulin, P., Koch, H. G., Wick, L., Sauter, B., Michel, D., \& Knecht, H. (2006). Paragliding accidents with spinal cord injury: 10 years' experience at a single institution. Spine, 31(10), 1125-1130. https://doi.org/10.1 097/01.brs.0000216502.39386.70

Gomes, R. M. (2009). Política da vida e a transparência do corpo. In O corpo e a política da vida (p. 13-41). Coimbra, Portugal: Centro de Estudos Biocinéticos.

Gomes, R. M., Pereira, A., Fraga, A. B., \& Ó, J. R. do. (2009). O corpo e a politica da vida. Coimbra, Portugal: Centro de Estudos Biocinéticos.

Graeff, F. G. (2003). Bases biológicas do transtorno de estresse pós-traumático. Brazilian Journal of Psychiatry, 25, 2124. https://doi.org/10.1590/S1516-44462003000500006

Karvonen, M. J., Kentala, E., \& Mustala, O. (1957). The effects of training on heart rate; a longitudinal study. Annales Medicinae Experimentalis Et Biologiae Fenniae, 35(3), 307-315.

Lipp, M. E. N., Frare, A., \& Santos, F. U. dos. (2007). Efeitos de variáveis psicológicas na reatividade cardiovascular em momentos de stress emocional. Estudos de Psicologia (Campinas), 24(2), 161-167. https://doi.org/10.159 0/S0103-166X2007000200003

Lopes, R. S. (2002). Parapente Brasil: Histórias e aventuras do vôo livre. Paraná; Curitiba: Copyright.

Nunomura, M., Teixeira, L. A. C., \& Fernandes, M. R. C. (2009). Nível de estresse em adultos após 12 meses de prática regular de atividade física. Revista Mackenzie de Educação Física e Esporte, 3(3). Recuperado de http://editorar evistas.mackenzie.br/index.php/remef/article/view/1325

Pagen, D. (2003). The secrets of champions. Canadá: Sport Aviation Publications.

Paixão, J. A., Tucher, G., Costa, V. L. M., \& Gabriel, R. E. C. (2010). Prática de parapente e comportamentos de risco: uma análise a partir do conceito de redoma sensorial. Psicologia em Estudo, 15(3), 8.

Pimentel, G. G. de A. (2010). Percepção dos riscos, condicionamento corporal e interações sociais no voo livre. Revista Brasileira de Ciências do Esporte, 31(2). Recuperado de http://www.revista.cbce.org.br/index.php/RBCE/artic le/view/703

Ramos, J. R. S. (2003). Esporte de aventura: um olhar praxiológico a partir dos praticantes de vôo livre da cidade de Niterói. In J. R. S. Ramos (Org.), Praxiologia motriz no Brasil: o discurso da ação motriz no Brasil: apontamentos para análise praxiológica em diferentes jogos, práticas corporais e brincadeiras (p. 71-82). Niterói: Erthal.

Samulski, D. M., Chagas, M. H., \& Nitsch, J. (1996). Stress: teorias básicas. Belo Horizonte: Editora Gráfica Costa \& Cupertino Ltda. 
Schulze, W. (2002). Injury prophylaxis in paragliding. British Journal of Sports Medicine, 36(5), 365-369. https://d oi.org/10.1136/bjsm.36.5.365

Semenoff, S. (1998). Curso de Paragliding: básico e intermediário. s.l.: Mimeo.

Sher, L. (2001). Role of endogenous opioids in the effects of light on mood and behavior. Medical Hypotheses, 57(5), 609-611. https://doi.org/10.1054/mehy.2001.1423

Slovic, P. (2010). The Psychology of risk. Saúde e Sociedade, 19(4), 731-747. https://doi.org/10.1590/S0104-1290 2010000400002

Thomas, J.R, Nelson, J.K., \& Silverman, S.J. (2007). Métodos de pesquisa em atividade física ( $\left.5^{\mathrm{a}} \mathrm{ed}\right)$. Porto Alegre: Artmed.

Vaz, P., Pombo, M., Fantinato, M., \& Pecly, G. (2007). O fator de risco na mídia. Interface - Comunicação, Saúde, Educação, 11(21), 145-153.

Weineck, J. (2005). Biologia do Esporte (7. ed). Barueri: Manole.

Wilmore, J. H., Costill, D. L., \& Kennedy, L. W. (2013). Fisiologia do Esporte e do Exercício (5. ed). Barueri: Manole.

Yuill, G. M. (1977). Icarus's syndrome: new hazards in flight. British Medical Journal, 1(6064), 823-825. https://d oi.org/10.1136/bmj.1.6064.823 